\title{
Mathematical Modelling of Fluid Motion in Borewell Filtering Devices
}

\author{
Bulchayev N.D. \\ Department of Exploration and Development \\ of Oil and Gas Deposits \\ Grozny State Oil Technical University \\ named after M.D. Millionshikov \\ Grozny, Russia \\ nbulchaev@yandex.ru
}

\section{Aliyev I.I.}

Department of Exploration and Development of Oil and Gas Deposits

Grozny State Oil Technical University named after M.D. Millionshikov

Grozny, Russia

ibr1377@gmail.com

\author{
Khaladov A.Sh. \\ Department of Exploration and Development \\ of Oil and Gas Deposits \\ Grozny State Oil Technical University \\ named after M.D. Millionshikov \\ Grozny, Russia \\ haladov_a_sh@mail.ru
}

Zeygman Yu.V.

Department of Exploration and Development

of Oil and Gas Deposits

Ufa State Petroleum Technological University

Ufa, Russia

kafedra-rngm@mail.ru

\author{
Kotenev Yu.A. \\ Department of Exploration and Development \\ of Oil and Gas Deposits \\ Ufa State Petroleum Technological University \\ Ufa, Russia \\ intnm@ya.ru
}

\begin{abstract}
The use of equations known in filtering theory to determine parameters of fluid motion through filters of various designs used in the oil industry to clean up the products from mechanical impurities is described. Analytical studies and calculations have been carried out to determine the speed of fluid motion in filters of frame-bar, ringed, perforating types, as well as through the packing of gravel filters. The selection of new boundary conditions simplifies the solution of the resulting differential equations; and the increase in the calculated parameters by $5-10 \%$ (Hou method) eliminates the probability of error. Thus, the obtained values of the filtering parameters allow to correctly choose the size and geometry of the filter elements.
\end{abstract}

Keywords - filtration flows, differential equatations, boundary conditions, average weighted potential, geometry of filter element, mechanical impurities

\section{INTRODUCTION}

In the practice of borewell operation, various types of filters are used: frame-rod, annular, perforated, gravel and others.

To solve practical problems of calculating filtration flows in a borewell, a single method for all types of filter designs is used. It is called the average weighted potential method
(AWP) [1], known in the technical literature as the Hou method [2]. Using this method, the value of debit underestimated by $5-10 \%$ is got. Therefore, it is enough to increase the result obtained by $7 \%$ to get as close as possible to the exact borewell flow rate.

\section{METHODS AND MATERIALS}

First the operation of the frame-rod filter is described. It consists of alternating vertical cracks and impenetrable walls (Fig. 1.). Obviously, by virtue of its symmetry, the surfaces of $\mathrm{AD}$ and $\mathrm{BC}$ will be the surfaces of the liquid current. The circular surface $C D$ is an equipotential surface on which the potential of the filtration velocity will be $\varphi=k P / \mu$, where $k$ is the formation permeability; $\mathrm{P}$ is the reduced pressure; $\mu$ is the dynamic viscosity of the fluid.

It is known that the potential of plane-parallel linear filtration in an isotropic medium with permeability $k$ satisfies the Laplace equation in polar coordinates $r, \theta[3,4]$ :

$$
\frac{\partial}{\partial r}\left(r \frac{\partial \varphi}{\partial r}\right)+\frac{\partial}{\partial \theta}\left(\frac{1}{r} \frac{\partial \varphi}{\partial \theta}\right)=0
$$



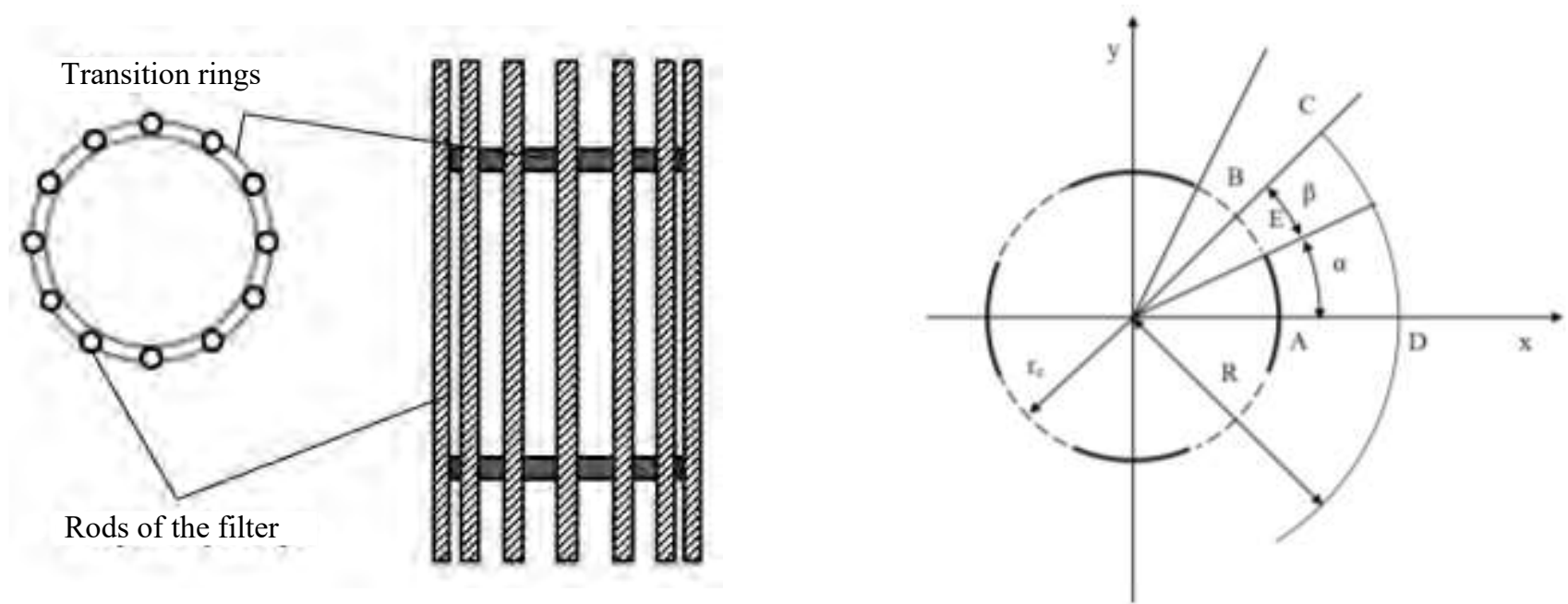

Fig. 1. Frame-core filter scheme used in water production borewells, $\mathrm{rc}-\mathrm{a}$ borewell radius, $\beta$ - half of the slit angle solution, $\alpha$ is half the impermeable wall angle solution, $\mathrm{R}$ - radius of the power loop

The boundary conditions for the Laplace equation for a frame-rod filter are as follows:

$$
\begin{gathered}
\left.\varphi\right|_{r=R}=\varphi_{\Pi}, \text { где } \varphi_{\Pi}=-\frac{k P_{\Pi}}{\mu}=\text { const }, \\
\left.\frac{\partial \varphi}{\partial \theta}\right|_{\theta=0}=0,\left.\frac{\partial \varphi}{\partial \theta}\right|_{\theta=\theta_{0}}=0, \text { где } \theta_{0}=\alpha+\beta \\
\left.\frac{\partial \varphi}{\partial r}\right|_{\substack{r=r_{c} \\
0 \leq \theta \leq \alpha}}=0 \\
\varphi_{\substack{r=r_{c} \\
\alpha \leq \theta \leq \theta_{0}}}=\varphi_{c}, \text { где } \varphi_{c}=-\frac{k P_{C}}{\mu}=\text { const }
\end{gathered}
$$

The exact solution to this problem will be given by the conformal mapping method. However, we are interested in the Hou method, which is the same for all filter designs. Therefore, instead of the exact boundary condition (5), the approximate boundary condition will be considered (6)

$$
\left.\frac{\partial \varphi}{\partial r}\right|_{\substack{r=r_{c} \\ \alpha \leq \theta \leq \theta_{0}}}=-V_{0}=\text { const }
$$

where $V_{0}-$ a certain, yet unknown, constant (the minus sign in (6) is because the fluid flow is directed to the center of the well). This constant will be selected so that the average value of the potential at the boundary BE satisfies the condition:

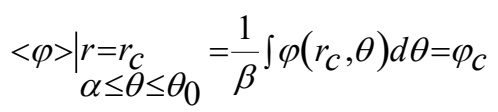

Condition (5) was fulfilled for the arithmetic mean value of the potential $\varphi$.
The Laplace equation (1), satisfying the boundary conditions (2), (3), (4), (6), is a differential equation with separable variables and has the form:

$$
\begin{gathered}
\varphi(r, \theta)=\frac{V_{O} r_{c}}{\theta_{0}} . \\
\left(\beta \cdot \ln \tau+2 \sum_{n=1}^{\infty} \frac{\left.\tau^{-\lambda_{n}}-\tau^{\lambda_{n}}\right] \sin \left(\lambda_{n} \alpha\right)}{\lambda_{n}^{2} \cdot\left[\tau_{0}^{-\lambda_{n}}+\tau_{0}^{\lambda_{n}}\right]} \cdot \cos \left(\lambda_{n} \theta\right)\right)+\varphi_{\Pi}
\end{gathered}
$$

where $\lambda_{n}=\frac{n \pi}{\theta_{0}}, \tau=\frac{R}{r}$ и $\tau_{0}=\frac{R}{r_{c}}-$ demensionless value.

The unknown quantity $V_{0}$ is found by calculating the potential value averaged on the $\mathrm{BE}$ arc. For this, the obtained value of potential (8) into formula (7) was substituted, from which we find that:

$$
V_{0}=\frac{\beta \theta_{0}}{r_{c}} \cdot \frac{\varphi_{c}-\varphi_{\Pi}}{\beta^{2} \cdot \ln \tau_{0}-2 \sum_{n=1}^{\infty} \frac{\tau_{0}^{-\lambda_{n}}-\tau_{0}^{\lambda_{n}}}{\tau_{0}^{-\lambda_{n}}+\tau_{0}^{\lambda_{n}}} \cdot \frac{\sin ^{2}\left(\lambda_{n} \alpha\right)}{\lambda_{n}^{3}}}
$$

The flow rate of the borewell will find using the found value $V_{o}$ according to the formula:

$$
Q=N 2 V_{O} S H=2 \pi \frac{k H}{\mu} \cdot \frac{P_{\Pi}-P_{C}}{\ln \frac{R}{r_{C}}+\frac{1}{2} \lambda},
$$

где $N$ - количество щелей на 1 погонный метр, $S-$ площадь щели, $H$ - высота фильтра.

where $\mathrm{N}$ - number of slots per linear meter, $\mathrm{S}$ - slot area, $\mathrm{H}$ - height of the filter. 


$$
\lambda=-\frac{4}{\beta^{2}} \sum_{n=1}^{\infty} \frac{\left(\frac{r_{c}}{R}\right)^{\lambda_{n}}-\left(\frac{R}{r_{c}}\right)^{\lambda_{n}} \sin ^{2}\left(\lambda_{n}\left[\frac{\pi}{N}-\beta\right]\right)}{\left(\frac{r_{c}}{R}\right)^{\lambda_{n}}+\left(\frac{R}{r_{c}}\right)^{\lambda_{n}} \cdot \frac{\lambda_{n}^{3}}{\lambda_{n}=N \cdot n}}
$$

The considered method suggests increasing the value of the $Q$ output by $7 \%$.

An annular filter consists of alternating horizontal cracks and impermeable rings (Fig. 2.). By virtue of the symmetry, the surfaces $\mathrm{AD}$ and $\mathrm{BC}$ can be considered as current surfaces. The circular cylindrical surface $\mathrm{CD}$ is an equipotential surface, on it the potential of the filtration rate is equal to some given constant. Like the first part of the paper, the problem is reduced to solving the Laplace equation (11) with respect to the potential $\varphi(r, z)$ in cylindrical coordinates [5]:

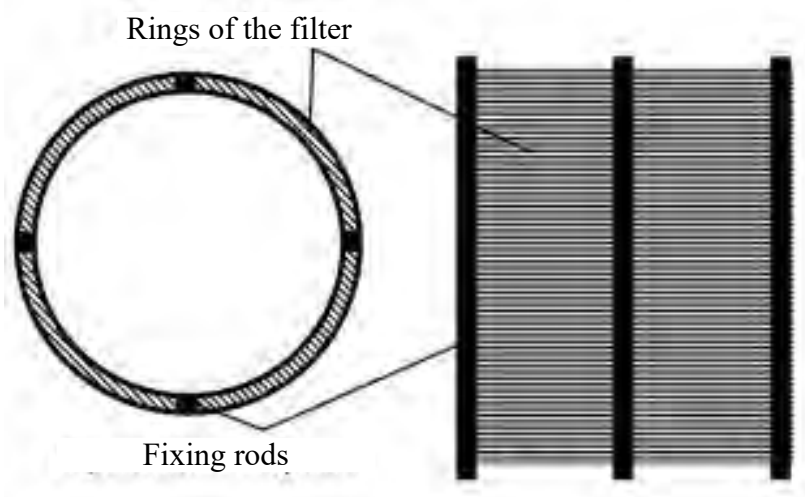

Fig. 2. Frame-core filter scheme used in water production borewells: $r_{c}$ - borewell radius; $l_{u}-$ half the height of the slit; $l_{c}-$ half the height of the impermeable wall; $R$ - the radius of the power circuit; $z_{0}=l_{u}+l_{c}$

For an approximate solution of this problem, the AWP method is applied. For this, instead of the boundary condition (15), the boundary condition is taken (16):

$$
\left.\frac{\partial \varphi}{\partial r}\right|_{\substack{r=r_{c} \\ 0 \leq \mathrm{Z} \leq l_{w_{m}}}}=-V_{0}=\text { const },
$$

where $V_{o}$ - some yet unknown constant (the minus sign in (16) means that the movement is directed to the center of the borewell).

The selection method is found so that the average value of the potential at the boundary AE satisfies the condition

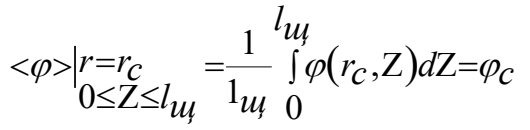

$$
\frac{1}{r} \frac{\partial}{\partial r}\left(r \frac{\partial \varphi}{\partial r}\right)+\frac{\partial^{2} \varphi}{\partial \mathrm{Z}^{2}}=0
$$

The boundary conditions in the region of ABCD (Fig. 2.) for equation (11) will be as follows:

$$
\left.\frac{\partial \varphi}{\partial \mathrm{Z}}\right|_{\mathrm{Z}=0}=0,\left.\frac{\partial \varphi}{\partial \mathrm{Z}}\right|_{\mathrm{Z}=\mathrm{Z}_{0}}=0
$$

$$
\left.\varphi\right|_{r=R}=\varphi_{\Pi} \text {, где } \varphi_{\Pi}=-\frac{k P_{\Pi}}{\mu}=\text { const },
$$

$$
\left.\frac{\partial \varphi}{\partial r}\right|_{\substack{r=r_{c} \\ l_{m_{\varphi}} \leq \mathrm{Z} \leq \mathrm{Z}_{0}}}=0,
$$

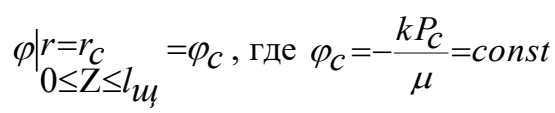

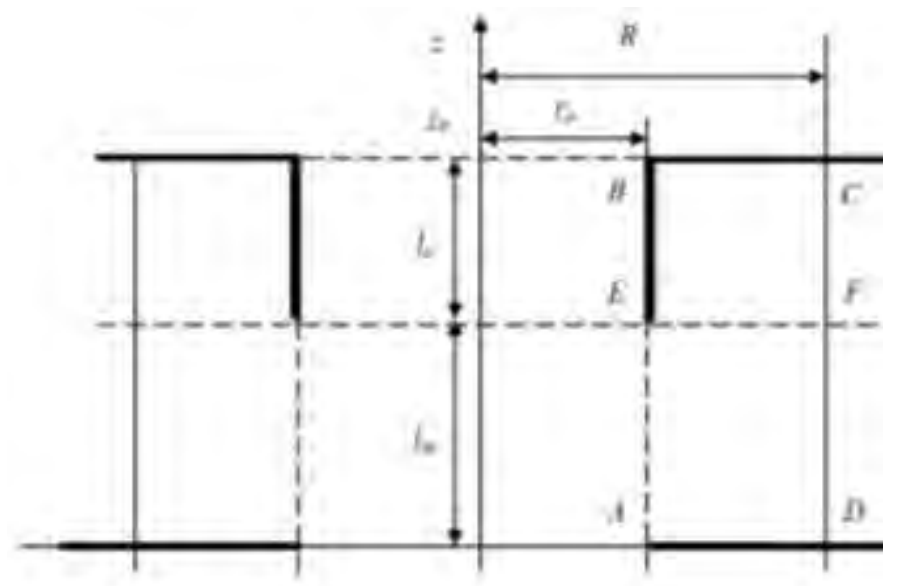

The Laplace equation (11) satisfying the boundary conditions (12), (13), (14), (16) is solved by the method of separation of variables and we get:

$$
\begin{gathered}
\varphi(r, z)=\frac{V_{0}}{z_{0}} . \\
\left(r_{c} l_{m} \ln \frac{R}{r}-2 \sum_{n=1}^{\infty} \frac{a_{n}(r)}{a_{n}\left(r_{c}\right)} \cdot \frac{\sin \left(\lambda_{n} l_{m}\right) \cos \left(\lambda_{n} z\right)}{\lambda_{n}}\right)+\varphi_{\Pi}, \\
\text { where } \quad \lambda_{n}=\frac{n \pi}{z_{0}}, \quad a_{n}(r)=\left|\begin{array}{l}
I_{0}\left(\lambda_{n} r\right) ; \\
I_{0}\left(\lambda_{n} R\right) ; K_{0}\left(\lambda_{n} r\right) \\
\lambda_{n}\left(\lambda_{n} R\right)
\end{array}\right|, \\
a_{n}(r)=\left|\begin{array}{l}
\lambda_{n} I_{1}\left(\lambda_{n} r\right) ; \lambda_{n} K_{1}\left(\lambda_{n} r\right) \\
I_{0}\left(\lambda_{n} R\right) ; K_{0}\left(\lambda_{n} R\right)
\end{array}\right|,
\end{gathered}
$$


where $I_{o}, I_{l}-$ modified Bessel functions; $K_{o} K_{l}-$ Macdonald functions [6].

Substituting the value of potential (18) into formula (17), we get:

$$
V_{0}=\frac{l_{u_{m} z_{0}} \cdot\left[\varphi_{c}-\varphi_{\Pi}\right]}{r_{c} l_{w}^{2} \ln \frac{R}{r}-2 \sum_{n=1}^{\infty} \frac{a_{n}\left(r_{c}\right)}{a_{n}\left(r_{c}\right)} \cdot \frac{\sin ^{2}\left(\lambda_{n} l_{w}\right)}{\lambda_{n}^{2}}}
$$

Using the obtained value of the filtration rate $V_{o}$, the flow rate is determined:

$$
Q=N V_{o} 2 \pi r_{c} 2 l_{u}=N V_{0} S=2 \pi \frac{k H}{\mu} \cdot \frac{P_{\Pi}-P_{c}}{\ln \frac{R}{r_{c}}+\frac{1}{2} \lambda},
$$
filter,

where $N$ - number of slots, $S$ - slot area, $H$ - height of the
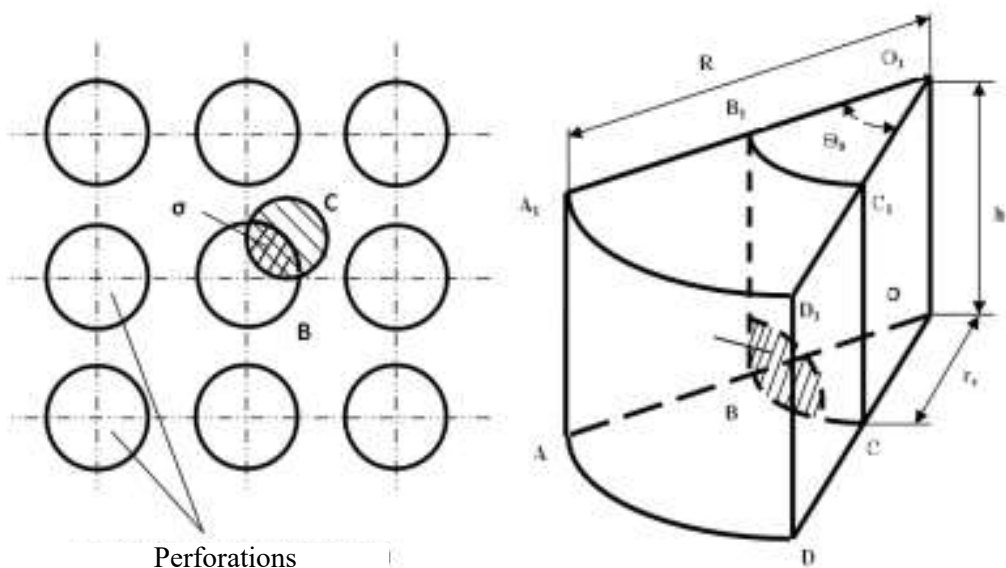

Fig. 3. The scheme of a filter perforated construction fragment with a row arrangement of perforations. On the left, the filter segment of an elementary flow area, $\mathrm{BB}_{1} \mathrm{C}_{1} \mathrm{C}-\mathrm{D}$ area of the filter surface, $\mathrm{OO}_{1}$ - the axis of symmetry of the wellbore, $\mathrm{h}$ - the height of the segment, $\theta_{0}-$ the angle of the segment solution, $\sigma-$ the fourth part of the perforation hole

Due to this symmetry, the surfaces $A B C D, A_{1} B_{1} C_{1} D_{1}$, $\mathrm{AA}_{1} \mathrm{~B}_{1} \mathrm{~B}$ and $\mathrm{DD}_{1} \mathrm{C}_{1} \mathrm{C}$ are current surfaces. The circular cylindrical surface $\mathrm{AA}_{1} \mathrm{D}_{1} \mathrm{D}$ is an equipotential surface on which the potential of the filtration rate $\phi$ is equal to a given constant. As in the two previous cases, the problem reduces to solving the Laplace equation in cylindrical coordinates $r, \theta, z$ :

$$
\frac{1}{r} \frac{\partial}{\partial r}\left(r \frac{\partial \varphi}{\partial r}\right)+\frac{1}{r^{2}} \frac{\partial^{2} \varphi}{\partial \theta^{2}}+\frac{\partial^{2} \varphi}{\partial z^{2}}=0
$$

Initial conditions:

$$
\left.\frac{\partial \varphi}{\partial z}\right|_{z=0}=0,\left.\frac{\partial \varphi}{\partial z}\right|_{z=h}=\left.0 \quad \frac{\partial \varphi}{\partial \theta}\right|_{\substack{\theta=0 \\ \theta=\theta_{0}}}=0
$$

$$
\lambda=-\frac{4}{r_{c} l_{u}^{2}} \sum_{n=1}^{\infty} \frac{a_{n}\left(r_{c}\right)}{a_{n}\left(r_{c}\right)} \cdot \frac{\sin ^{2}\left(\lambda_{n} l_{u_{c}}\right)}{\lambda_{n}^{2}}
$$

Computational experiments showed that the flow rate increases with increasing filter duty cycle and approaches the asymptotic value at $20-30 \%$ duty cycle (Fig. 3). Therefore, there is no practical need for ringed filters with a higher duty cycle. In practice, indeed, they use filters of the ringed construction with a duty cycle from $20 \%$ to $30 \%$ [7].

For a perforation-type filter, the flow rate equation is obtained by analogous calculations considering its features (Fig. 3)

The holes in the cylindrical body of this type of filters can have different geometric shapes and sizes. The problem of calculating the flow rate for the row arrangement of perforation holes is described. These holes have two perpendicular axes of symmetry, one of which is parallel to the axis of the borewell; and they include a rectangle, circle, ellipse, and others (Fig. 3). 


$$
\begin{gathered}
Q=N V_{o} 4 S_{\sigma} r_{c}=N V_{0} 4 S=2 \pi \frac{k H}{\mu} \cdot \frac{P_{\Pi}-P_{c}}{\ln \frac{R}{r_{c}}+\frac{1}{2} \lambda}, \\
\lambda=-\frac{8}{r_{c} S_{\sigma}^{2}} \sum_{m=1}^{\infty} \sum_{n=1}^{\infty} \frac{W_{m n}\left(r_{c}\right)}{W_{m n}\left(r_{c}\right)} S_{m n}^{2}
\end{gathered}
$$

where $N$ - total number of perforations, $\mathrm{S}=S_{\sigma} r_{c}$ - the area of the perforation, $\mathrm{H}-$ the height of the filter.

\section{RESULTS}

Computing experiments performed on the basis of the obtained formulas for the flow rates of borewells showed (Fig. 4) that the flow rate of a perforation filter approaches the asymptotic value at a $20-25 \%$ duty cycle $[8,9]$. Therefore, there is no practical need to create a perforation filter design with a duty cycle greater than $20-25 \%$. This conclusion corresponds to the practice in which indeed the filters of this design are used with a duty cycle from $17 \%$ to $23 \%$.

According to the results, it is possible to recommend the use of perforated filters in practice. This design is characterized by high throughput at low duty ratio, which allows the filter to provide the necessary strength properties.

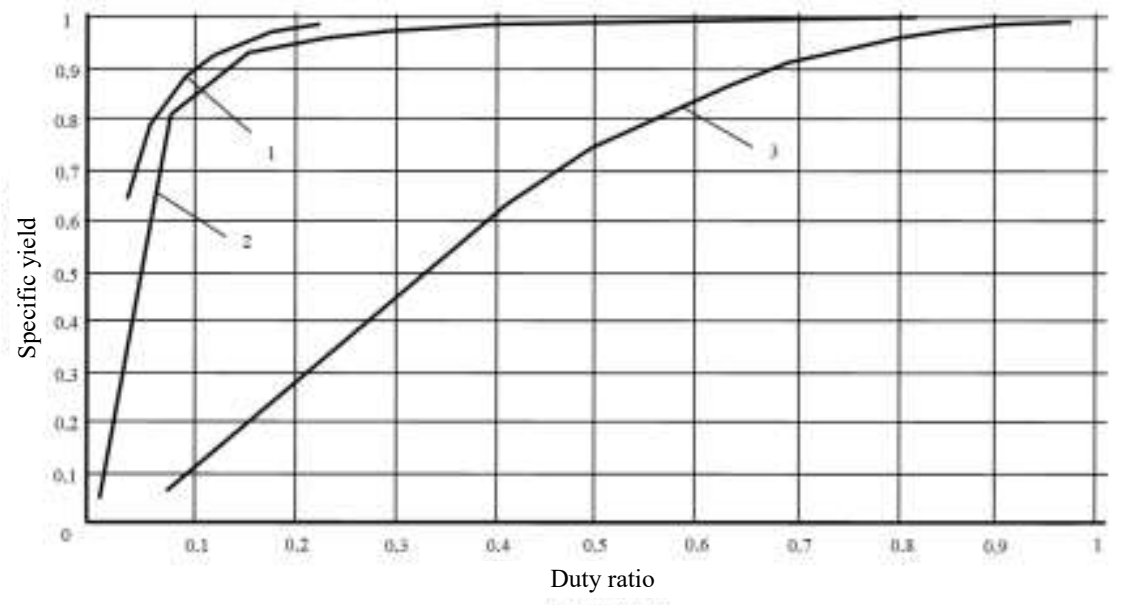

Fig. 4. Comparison of filters of various designs.

Filter of perforation design, quality of perforation holes around 32 holes, solution angle of holes -2.87 degrees, hole height $-115 \mathrm{~mm}$, number of holes per 1 meter vertically from 1 to $8 ; 2$. Ringed filter, slot height $-1.5 \mathrm{~mm}$, number of slots per meter height from 1 to $666 ; 3$. Frame-rod filter design, the angle of the slit solution -25 degrees, the number of slits is from 1 to 14 .

The calculations were carried out according to the formulas for determining the flow rates for frame-bar, ringed and perforation types of filters (borewell radius $100 \mathrm{~mm}$, power supply radius $200 \mathrm{~m}$ ) [10].

\section{CONCLUSION}

Filtering devices do not fully solve the problem of protecting the unit of electric submersible centrifugal pump, tubing from the harmful effects of mechanical impurities, mainly represented by quartz sand, loose particles of proppant, killing fluid, etc. When using such devices in order to prevent the formation of traffic jams at the bottom of a well, various containers and fishing chambers are often used [11].

However, the percentage of success of such measures depends on the concentration and fractional composition of suspended particles [12]. Therefore, the greatest effect on the protection of pumping and other equipment from mechanical impurities is achieved with a comprehensive solution to the problem.

It will be important is the work to reduce the water-cut of production borewells, to control the selection, etc.

\section{References}

[1] V.N. Nikolayevskiy, "On the exact and approximate solutions of a single flat filtering problem under mixed boundary conditions", Bulletin of the Soviet Academy of Sciences, Vol.10, 1957. pp. 102-105.

[2] R.F. Fikhmanas, P.Sh. Fridberg, "Howe method of calculating the capacity of bodies and its connection with the variational principles", Technical Physics, vol. 6 (40), 1970, pp. 1327-1328.

[3] V. P. Pilatovskiy, Hydromechanics basics of thin bed. Moscow: Nedra, 1966, p. 318.

[4] I.N. Bronschtein, K.A. Semendyayev, Handbook of mathematics for engineers and students. Moscow: Nauka, 1986, p. 544.

[5] L.G. Loytsyanskiy, Fluid and gas mechanics. Moscow: Nauka, 1983, p. 520.

[6] P.Ya. Polubarinova-Kochina, Theory of groundwater movement Moscow: Nauka, 1977, p.537. 
[7] M.Yu. Tarasov, "Study of the process of mechanical impurities separation from highly viscous products of wells:, Oil industry, vol. 11. pp. 122-124.

[8] V.F. Bocharnikov, Reference for the repair of oil and gas equipment, vol. 2. Moscow: Infra-Inzheneriya, 2015, p.576.

[9] V.N. Ivanovskiy, V.I. Darishchev, A.A. Sabirov, et al, Well pumping installations for oil production. Moscow: Gas and Oil, 2002, p.824.

[10] L.V. Igrevskiy, Improving the efficiency of operation of pump-ejector systems for oil production: Engineering Cand. Diss. Moscow, 2002.
[11] N.A. Bakhshyan, N.D. Bulchayev, In proc. pp.152-159, 2018 [Prospects for the fuel and energy complex development and the current state of oil and gas engineering education in Russia. Scientific and technical conference dedicated to the 105 th anniversary of M. D. Millionshchikov, 2015].

[12] A.Sh. Khaladov, A.M. Bondarchuk, S.S. Gots, K.Sh. Amaletdinova, I.R. Fakhretdinov, V.P. Otochin, "Processes modelling for managing fluid accumulation in sewage treatment plants", Oil industry, vol. 9., 2008, pp. 94-95. 